\title{
Entre o desejo e a necessidade de aprender línguas: algumas reflexões sobre o que também está em jogo nesse processo ${ }^{1}$
}

\author{
Between the Desire and the Need to Learn \\ Languages: Some Thoughts about What is \\ Also at Stake in this Process
}

Eliane Righi de Andrade*

Instituto de Estudos da Linguagem - Unicamp

\begin{abstract}
RESUMO: Neste estudo de natureza discursiva, nossa proposta é, partindo do dizer de alunos-professores em formação, identificar parte do imaginário construído e descrito por eles sobre o aprender línguas, utilizando-nos de conceitos básicos da psicanálise (desejo e necessidade) e de Foucault (principalmente, o das tecnologias de si). Através da análise de recortes selecionados de entrevistas orais, podemos concluir que aprender línguas implica muito mais do que a aquisição de saberes, habilidades e competências, mas toda a reconfiguração de processos subjetivos e identitários que constituem o sujeito-professor, processos inconscientes que remetem ao caráter ameaçador do desejo e ao caráter regularizador/normatizador das necessidades, que se constituem a partir das relações simbólicas e imaginárias produzidas na e pela história.
\end{abstract}

PALAVRAS-CHAVES: língua estrangeira; necessidade; desejo.

ABSTRACT: Based on a discoursive perspective, this article intends to analyze some discoursive segments produced by undergraduate teachers in oral interviews, searching for identifying some foreign language representations of learning, which can appear in their speech. As a theoretical support, we are going to develop two concepts from psychoanalysis (need and desire), and also the idea of technologies of the self, developed by Foucault in his work. Considering the results of the analysis, we can conclude that learning a foreign language requires not only specific knowledge, such as vocabulary or grammar, but also involves unconscious processes which constitute the subject and his/her identity as a teacher. This

\footnotetext{
* elianerighi@terra.com.br

${ }^{1}$ Este artigo foi produzido a partir de parte do corpus e de algumas reflexóes que fazem parte da tese de doutorado em desenvolvimento, orientada pela profa. Maria José Coracini, do IEL - Unicamp.
} 
identity, however, is conditioned by history and social meanings, which are produced by symbolic and imaginary relations.

KEYWORDS: foreign language; need; desire.

\section{Introdução}

A proposta deste trabalho é discutir, a partir da análise de recortes discursivos, selecionados a partir de entrevistas orais com alunos-professores do último ano de licenciatura dupla em Letras, diferentes aspectos que estão em jogo na constituição da subjetividade desses alunos-professores e que interferem não só no imaginário sobre o ensino-aprendizagem de língua estrangeira, mas também sobre uma desejada identidade com a qual o sujeito se projeta no mundo.

A noção teórica de "identidade" da qual partimos baseia-se numa visão de processo em constante mutação e construção e que se dá via diferentes práticas e discursos. O sujeito do qual falamos é o da linguagem, uma vez que é aquele que se faz sujeito no e pelo discurso. Seu engajamento no discurso se dá via história e língua, na qual seu dizer se materializa. Por estar imerso na linguagem, este sujeito está, portanto, à mercê de sua equivocidade e das formações inconscientes que atravessam a língua na qual se diz ou tenta se dizer. Se, por um lado, deseja, conscientemente, o controle do dizer, por outro, ao qual não tem domínio, deixa fluir a multiplicidade que constitui a si e seu dizer.

Considerando tais pressupostos teóricos, passemos para uma breve conceituação do que entendemos por "desejo" e por "necessidade", termos que apresentamos lado a lado, no título dessa reflexão, exatamente por entender que ambos estão imbricados na aprendizagem de línguas e na construção do sujeito-professor em formação.

\section{Desenvolvendo o conceito de necessidade e desejo articulados à demanda}

Percorrendo a teoria psicanalítica, a necessidade aparece na tríade necessidade-demanda-desejo, que remonta, primariamente, segundo Nasio (1993[1992]), ${ }^{2}$ à teoria freudiana das pulsóes. Por essa perspectiva, a necessidade encontrar-se-ia, para o indivíduo, no plano de uma exigência

\footnotetext{
${ }^{2}$ Os colchetes indicam a data da primeira edição da obra. Entre parênteses, encontrase a data da edição utilizada neste trabalho, a qual será indicada, a partir de então, nas outras citaçóes que houver da mesma obra.
} 
fisiológica, como a fome, por exemplo. Esta poderia ser cessada mediante sua satisfação, na assimilação de um alimento.

Quanto à demanda, esta já ocorreria no plano da linguagem; envolveria, portanto, uma "fala" entre um sujeito e um "outro", numa ação conjunta e recíproca: por exemplo, por parte da criança, o pedido de algo e, por parte da mãe, o oferecimento de algo que "interpreta" como sendo o pedido da criançadaí atribuir um sentido àquela demanda.

Se falamos do campo da linguagem - portanto, da ordem do simbólico -, a demanda implica em falta, pois a língua falha, a língua é equívoca: aquilo que é oferecido à criança e poderia satisfazer uma necessidade sua, nunca poderá satisfazer o desejo que a demanda evoca (um "objeto" perdido no real), pois não há "objeto" capaz de suprir algo que não tem forma, que não pertence ao campo do sujeito, nem ao campo do Outro (inconsciente), daí não poder ser simbolizado. Lacan, paradoxalmente, associa esse desejo à "causa" do sujeito, nomeando-o como objeto $a$, um objeto que se perdeu no momento em que o sujeito se fez na linguagem (o sujeito concede, ao mesmo tempo, que a linguagem o habite e o limite). Assim, a demanda precisa de um objeto, mas permanecerá sempre insatisfeita, ainda que objetos parciais de satisfação possam ser oferecidos ao sujeito, aplacando a sua falta constitutiva e, ao mesmo tempo, "impulsionando" a energia causadora do desejo.

Quanto à conceituação psicanalítica de desejo, trazemos algumas observações de Fink (1998 [1995], p.116), que aponta que o desejo, a rigor, não tem objeto e é algo que não é articulado na/pela linguagem. No entanto, somente como desejo socialmente compreensível é que lhe pode ser atribuído um "sentido" - na tentativa de simbolizá-lo. Assim, o desejo é moldado na/pela língua que se aprende, a partir de uma necessidade "criada", perdendo seu contato com o real, registro no qual ele se apresenta, primeiramente, como o resto que não foi - nem poderá ser - simbolizado. Assim, com a expressão do desejo pelo "modo ego" (eu quero), procura-se "domar" sua natureza de inapreensível, de estranho e inassimilável - aquilo que Lacan caracteriza de "ameaçador".

Fink (1998) estabelece a relação do desejo com aquilo que é inconsciente, uma vez que é inapreensível pelo simbólico, mas que vaza nos momentos de equivocidade da língua (nos lapsos, por exemplo). Uma vez que o desejo está circunscrito ao inconsciente e o inconsciente é habitado pelo Outro (pela linguagem, pela cultura, pela demanda de amor, pelo objeto $a$, pelo objeto de gozo etc.), podemos afirmar que este desejo é, de certa forma, estranho ao sujeito, ou seja, nem sempre corresponde a algo que efetivamente o sujeito 
quer, mas corresponde a desejos de outros. Nesse caso, há um desejo com o qual o sujeito se debate e que o força a agir, embora ele possa não senti-lo como um desejo internamente seu.

Na tentativa de se apreender o desejo - por meio do simbólico, atribuindo sentido às demandas do sujeito, através da língua -, este é recortado do real e transformado em demandas que não correspondem, propriamente, ao objeto primeiro causador de desejo do sujeito, já que é o Outro que faz a "leitura" desse desejo. O que resta é o objeto a, que se perde no encontro com esse Outro.

Ampliando o conceito primeiro de necessidade, poderíamos dizer, então, que esta se desvia, significativamente, de seu caráter "orgânico" e assinala uma relação bastante estreita com a noção de demanda, no que tange a uma necessidade ditada socialmente (daí ser expressa no dizer como demanda), mas assumida, muitas vezes, pelo sujeito, como vontade própria. Além disso, a necessidade se articula à historicidade, o que a coloca em contato com a sociedade de consumo na atualidade.

Numa outra vertente teórica, trazemos, ainda, algumas observações de Castoriadis (1986 [1975], p.180), que resgata, no conceito de necessidade, a relação com o mundo social. $\mathrm{O}$ autor considera que a necessidade se torna um requisito social em função de uma elaboração cultural - questão que toca a temática freudiana da cultura (FREUD 1996[1919]). Essa elaboração se dá numa complexa relação de fatores, tais como as disponibilidades naturais e técnicas, os jogos simbólicos e a conjuntura sócio-histórica, configurando o que chamaremos "agenciamentos". As escolhas que determinam se um objeto é "necessário" ou não estão circunscritas, portanto, a "um sistema de significações imaginárias que valorizam e desvalorizam, estruturam e hierarquizam um conjunto cruzado de objetos e de faltas correspondentes" (CASTORIADIS, 1986, p.181).

Segundo o autor, a racionalidade capitalista das sociedades (pós)modernas se manifesta no predomínio do imaginário, no qual o conceito de necessidade ultrapassa a concepção vigente daquilo que é tido como básico para tomar a forma de demandas de consumo. Observa-se, assim, a "fabricação histórica das necessidades que são manufaturadas todos os dias sob nossos olhos" (Idem, Ibidem, p.188), o que significa transformá-las em demandas de consumo a serem satisfeitas.

O caráter "funcional" da necessidade é posto de lado pelo imaginário social do capitalismo moderno, uma vez que tal economia só pode existir e funcionar a partir do momento em que cria "respostas" a "necessidades" que 
ela mesma produz dentro do sistema. Essas necessidades fazem parte dos agenciamentos produzidos na sociedade e que remetem aos modos de conduta dos indivíduos, através da incorporação de "tecnologias de si".

Tal conceito, trabalhado inicialmente por Foucault (2004a, p.199), remete ao conjunto de técnicas ao qual o indivíduo se submete "voluntariamente" para reger a si próprio, sua vida, a de sua família e a de todos os membros da sociedade, em função do bem coletivo, objetivado pela administração governamental. As tecnologias do eu - ou de si, como as chama Foucault (2004a) - estão em estreita relação com a arte de governar e com os agenciamentos que administram os indivíduos, seus desejos e suas necessidades, criando certos modos de existência aos quais eles estão sujeitos.

Rose (2001a, p. 38), que parte dos estudos foucaultianos para desenvolver sua teoria sobre tecnologias, afirma que "as tecnologias humanas são montagens híbridas de saberes, instrumentos, pessoas, sistemas de julgamento, edifícios e espaços" que orientam a vida dos seres humanos em um determinado tempo e espaço, pois há agenciamentos - que ele denomina também "maquinações" (ROSE, 2001b), a partir da teoria deleuziana - que são possíveis, somente, num determinado contexto histórico, sob certas condiçōes de produção.

É possível, portanto, estabelecer relações entre as tecnologias de si, expressas em agenciamentos, com o conceito de desejo, exposto pela psicanálise. Forbes (2005 [2003]) - embora não utilize especificamente esse termo - faz uma articulação interessante entre o que aqui apresentamos como agenciamento e a noção de desejo. Isso porque coloca que o caráter fundamental do desejo é sua natureza desconhecida, que o remete à dúvida e à incerteza. Daí as pessoas fugirem das decisões que envolvem riscos, preferindo voltar-se ao mundo da certeza, onde, basicamente, cumprem ordens ditadas pelas ciências, pelas religiôes, ou seja, por quaisquer formas de agenciamento. Essa maneira de evitar riscos é, de certa forma, útil à arte de governar os indivíduos (FOUCAULT, 2004b) - à política, conceito utilizado por Forbes (2005, p.69) para caracterizar esse agenciamento. As ordens podem ser encaradas, no mundo social, como necessidades e demandas às quais o sujeito deve se submeter, em nome de seu "conforto" e dos outros indivíduos, formatando, assim, seu desejo - e toda a energia criadora e desafiadora que o envolve - a essas injunções sociais.

Correr risco, segundo o autor, implica que o sujeito se responsabilize por suas decisões - por aquilo que move seu desejo. No entanto, o mundo 
normatizado gera a pasteurização das subjetividades e, segundo Forbes (2005, p. 86), há uma "tentativa da ortopedia geral da satisfação humana".

Trazendo tal princípio da teoria psicanalítica para a discussão da construção das subjetividades, isso significa que, socialmente, procura-se aliar o "objeto" causador do desejo (nomeado como objeto a na psicanálise lacaniana e que remete à falta constitutiva) às necessidades impostas pelo mundo social, transformando o desejo de completude que o move em demandas a serem satisfeitas. Portanto, nessa tentativa de apreensão do objeto $a$, o desejo é expresso na transitividade como um "desejo de" e não como algo causador do desejo, ou seja, não como uma energia criadora que impulsiona o homem, transformando-o em sujeito. Ainda segundo o autor, nada que alguém possa querer é suficiente para satisfazer o desejo: desejar não é obter uma coisa que se quer ou que satisfaça uma necessidade, mas algo que remete, sempre, à falta.

Em relação ao desejo, no que tange à problemática de ensinoaprendizagem de línguas, Prasse (1997, p. 65) aponta, por um lado, a condição de incompreensibilidade do desejo e, por outro, a tentativa de simbolizá-lo como um desejo das línguas estrangeiras, ou seja, tornando-o um desejo transitivo (um desejo de língua estrangeira), pois o sujeito teria, então, a oportunidade de colocar, na aprendizagem de uma língua estrangeira, a escolha de uma lei (a ordem simbólica) à qual quer se submeter. Esta seria uma possibilidade para o sujeito "se aproximar" de seu desejo inconsciente (PRASSE, 1997, p.71-72). Além disso, essa língua constituiria para ele, também, um objeto de cobiça, inveja, já que seria nela que o sujeito acredita que o estrangeiro (o outro) pode "gozar". Se, para o sujeito, esse gozo é estruturalmente impossível de se realizar na (e pela) língua materna - uma vez que ele jamais se dirá por completo -, ele "alucina” esse outro lugar melhor, onde a diferença se instaura.

Cabe-nos, então, nesta breve reflexão, investigar como desejo e necessidade imbricam-se no dizer dos alunos-professores de língua estrangeira (especialmente língua inglesa), revelando pequenos rastros de sua constituição subjetiva e de sua identidade.

\section{O trabalho de análise do corpus: buscando representações}

O corpus de pesquisa - do qual retiramos alguns recortes para este estudo - foi constituído a partir da transcrição de entrevistas orais com um grupo de alunos-professores de um curso de Letras, com licenciatura dupla. Este curso noturno, ministrado numa instituição particular, tem duração de 3 anos e reúne 
alunos de faixas etárias bastante diversas. Do grupo de dez entrevistados, selecionamos, para esta discussão, recortes de dois alunos-professores, os quais identificaremos como A1 e A3, ${ }^{3}$ respectivamente. Ambos participantes são do sexo feminino e já atuam como professoras no ensino público, embora não especificamente na disciplina de língua estrangeira: considerando a nomenclatura do antigo sistema público de ensino, A1 é professora de todas as matérias de $1^{\mathrm{a}}$. a $4^{\mathrm{a}}$. séries e $\mathrm{A} 3$ é professora eventual de $5^{\mathrm{a}}$. a $8^{\mathrm{a}}$. séries).

Iniciemos por um recorte de $\mathrm{A} 1 \mathrm{em}$ que esta descreve um imaginário em torno da língua inglesa antes de ingressar no ensino formal:

$\mathrm{RD}^{4} 1$ : Eu ficava deslumbrada! $/ 5$ Assim como eu percebo que os meus alunos também ficam// A gente tem vontade de traduzir tudo/ quer saber o que significa/ principalmente em relação à música// Eu penso muito nisso/ que a gente sempre teve vontade de saber o que significava as letras de músicas/ então eu tinha vontade de saber... curiosidade/ acho que.../ o que leva a criança e o adolescente é a curiosidade que corresponde/ que aquele cantor que pega aquela melodia tão bonita/ mas o que ele quer dizer...// Então eu acho que antes eu tinha uma curiosidade em relação à língua/ vontade de saber realmente o significado

Nesse primeiro recorte discursivo, A1 narra seus primeiros contatos com a língua estrangeira (inglês), antes de qualquer atividade de aprendizagem formal. Ao se dizer "deslumbrada" ao ter contato com a língua inglesa (sensação que também "identifica" em seus alunos), o eu-enunciador parece se remeter a uma experiência maravilhosa, inigualável. Comparamos, aqui, tal sentimento com o da paixão, também causadora de um aniquilamento que atinge o sujeito por desespero ou excesso (BARTHES, 1990 [1977] p. 42). Sugere um sentimento em relação à língua sobre o qual o sujeito não tem controle e pelo qual é capturado (algo lhe causa o deslumbramento), colocando-o em uma posição de passividade em relação ao objeto amoroso.

\footnotetext{
${ }^{3}$ A letra $A$ foi utilizada para identificar cada um dos alunos-professores entrevistados, acompanhada de um número que se refere à ordem em que as entrevistas foram realizadas. ${ }^{4}$ As letras $R D$ referem-se às iniciais de recorte discursivo.

${ }^{5} \mathrm{Na}$ transcrição, a barra (/) indica uma pausa breve e pode ser seguida por letra maiúscula, caso insira uma mudança de assunto, ou por letra minúscula, quando corresponde apenas a uma pausa na fala. As barras duplas (//) indicam pausa mais longa.
} 
Entretanto, no uso de outras expressões que acompanham seu dizer ( $A$ gente tem vontade de traduzir tudol quer saber o que significal tinha vontade de saber... curiosidade), o eu assume a posição ativa sobre o objeto amado e, nessa posição, busca ter controle sobre ele, como se fosse possível atingir sua completude, "traduzindo tudo". Traduzir parece ser a tentativa de dominar o desconhecido, o estranho que constitui, para o sujeito, a língua estrangeira.

O deslumbramento frente à língua estrangeira seria um desses sentimentos que não se compreendem, que não se explicam no/pelo dizer consciente. $\mathrm{O}$ ato de traduzir, portanto, parece identificado, aqui, à possibilidade de "dominar" a estranheza da língua do outro, objeto da paixão, que lhe é um desconhecido, mas que o atrai (o deslumbra). Daí os dizeres "vontade de saber" e "curiosidade" retomarem a idéia de um sujeito racional, centrado, que tenta ter controle sobre o que diz e sobre as sensaçôes que a língua "estranha" lhe causa.

Notamos, ainda, no dizer de A1, como as palavras vão sendo acrescentadas ao fio discursivo, apresentando uma seqüência de expressões com elementos que se repetem e outros novos, pelos quais se processam pequenos deslizamentos de sentido, mas que guardam, no entanto, certa semelhança com os anteriores, da cadeia discursiva: "a gente tem vontade de traduzir tudo"; "quer saber o que significa/principalmente em relação à música"; "a gente sempre teve vontade de saber o que significava as letras de música"; "tinha vontade de saber... curiosidade"; "o que leva a criança e o adolescente é a curiosidade..."; "acho que antes eu tinha uma curiosidade"; "vontade de saber realmente o significado". Essa relação que se estabelece entre os significantes nos parece remeter, no discurso, a uma cadeia metonímica, na qual os significantes vão sendo desdobrados em outros, caracterizando, pelo excesso, a falta constitutiva do dizer.

Se considerarmos a metonímia como um processo de deslizamento em que algo se mantém do sentido, o dizer desse enunciador se constrói, basicamente, sobre repetições (o discurso do mesmo numa materialidade que, às vezes, é diferente), sobre um conjunto de imagens recorrentes, com as quais se elabora, simbolicamente, muito pouco ou nada sobre o objeto amoroso a língua estrangeira, cujo papel seria o de um objeto substituto do desejo. Esse objeto amoroso restringir-se-ia, assim, à ordem do imaginário. Por isso, fica mais fácil para o sujeito trocá-lo a seu bel-prazer. Vejamos, no recorte a seguir, como se processa essa substituição: 
RD2: É... eu fiquei com me... assustada./ Foi difícil!/ Foi difícil!/ A gente .../ ainda sinto muita dificuldade na língua inglesa// Foi.../ ao mesmo tempo que foi gratificante/ foi assustador!/ Fiquei com medo... não ía dar certo// Tanto que eu relutei...// Na verdade, eu tô fazendo a língua inglesa/ porque não tem opção de língua espanhola/ a minha vontade era fazer língua espanhola/ porque é uma relutância.../ eu tenho que já... já.../ que eu acho que não vou aprender// Acho que é muito difícil/ porque é muito fora do meu contexto/ e eu fiquei assustada./ Eu sabia que eu ia ter muita dificuldade

Aquela língua estrangeira que, segundo o dizer do enunciador, causava o sentimento de deslumbramento é, então, trocada por um novo objeto (parcial) de "desejo", aqui assumido como um objeto de demanda de consumo: a língua espanhola - a qual parece estar relacionada estritamente ao registro imaginário do sujeito.

Há várias outras considerações, ainda, que podemos fazer a partir desse recorte. Primeiramente, o inglês é colocado sob a perspectiva do estranho, daquilo que está "fora do contexto", o que implica colocar essa língua num certo distanciamento em relação à constituição subjetiva de A1, como algo "fora de si”: daí causar medo (eu fiquei assustada). Segundo Freud (1996 [1920]), o medo exige um objeto definido sobre o qual recaia o temor; já o susto é causado frente a algo que o sujeito considera um perigo e para o qual seu sistema psíquico não está preparado. A língua inglesa coloca-se, então, para este sujeito, associada a esses sentimentos ameaçadores, justificando a dificuldade em aprendê-la pelo fato de considerá-la "muito fora de seu contexto".

Aprender a língua exigiria, portanto, desse enunciador, um certo deslocamento em relação à sua subjetividade, o que se revela como uma impossibilidade, pois o sujeito resiste a essa mudança (eu relutei; é uma relutância). A língua é uma ameaça, talvez, para a sua identidade construída numa outra língua (geralmente, naquela que lhe fez sujeito e que é identificada como a língua materna). Nessa língua materna, o sujeito - bem como sua identidade - ver-se-ia numa situação de conforto, de estabilidade, estado que é buscado, segundo a psicanálise, no princípio do prazer (FREUD, 1996). O sentimento de familiaridade é identificado, pelo enunciador, por outro lado, com a língua espanhola, língua com a qual sente certa proximidade. Vejamos o recorte 3:

RD3: Eles têm uma.../ a língua que tem uma melodia/ que parece cantada/ que tem um charme/ Eu lembro que eu trabalhava na $\mathrm{X}$ 
[nome da empresa] e tinha um gerente argentino/ da Argentina mesmo/ que veio para o Brasil// quando ele foi dar uma palestra pra gente/ ele começava a falar devagar... portunhol/ né?/ a gente entendia

A familiaridade com o espanhol remete à pesquisa já realizada por Celada (2002), que aponta o "portunhol" como parte do imaginário de muitos brasileiros. Assim, o que pode ligar A1 à língua espanhola é um desejo de manter-se, o máximo possível, próximo à língua dita materna (o português), evitando o confronto com o estranho (língua inglesa). Se a "familiaridade" é buscada, a língua estrangeira perde seu caráter instaurador da diferença no sujeito, em sua subjetividade, já que, em outra língua, haveria a possibilidade de ele se dizer de outras formas, de se constituir diferentemente. Nesse caso, o imaginário de língua estrangeira constrói-se, portanto, em torno de algo que parece externo ao sujeito; daí a língua inglesa estar associada a um "fora".

Retomando o recorte 2, notamos, ainda, que A1, em seu dizer, não se coloca como responsável pela escolha de estudar o inglês na faculdade: a instituição é que não oferece o curso de espanhol que gostaria de fazer. Assim, a escolha se mostra nas mãos de um outro; o sujeito se coloca, então, numa relação de passividade frente às opções que poderia ter e fazer, como se fosse exclusivamente um objeto do outro e um produto desse agenciamento escolar.

Numa primeira possibilidade interpretativa para essa análise, poderíamos sugerir que o espanhol estaria, de alguma forma, relacionado ao indecifrável, indefinível objeto causador de desejo no sujeito (objeto a), ainda que este tenha se perdido no momento em que o sujeito ingressou na ordem do simbólico, a partir da impossibilidade de (se) dizer por completo numa língua (inclusive, na materna). Isso "justificaria" o desejo do sujeito de buscar tudo dizer e de se dizer por completo, na língua do outro, ou seja, de fazer nessa língua o "empenhamento" de seu desejo. Numa segunda hipótese de interpretação, no entanto, poderíamos considerar que o sujeito teria escolhido a língua espanhola como objeto parcial de satisfação - um objeto, portanto, substituto do desejo -, para tentar "tamponar" uma falta que lhe é constitutiva, não assumindo as conseqüências desse desejo e afastando-se, assim, dos sentimentos que o envolvem, tais como o medo, a surpresa e o deslumbramento, sentimentos esses que revela em sua narrativa sobre a língua inglesa, considerada em sua "estranheza" radical.

Notamos, enfim, que as imagens que o enunciador constrói, em sua narrativa, para descrever língua(s) estrangeira(s), são representaçōes predominantemente da ordem do imaginário, que se apresentam mais ou menos fixas, 
imutáveis: o inglês é difícil, fora do contexto; o espanhol tem uma melodia, parece cantado, tem charme, pode ser entendido. Estas representações são corroboradas pelo senso comum e pelo social, daí a sua "identidade" de alunoprofessor se manter, aparentemente, a mesma, após a experiência de "aprendizagem" da língua estrangeira.

O processo de aprendizagem, portanto, não parece ter desencadeado uma nova relação com a língua do outro/Outro. ${ }^{6}$ Ela se mantém num "forade-si" do sujeito, embora este se revele centrado em si mesmo e nas identificaçóes imaginárias que se colocam no plano do especular, daí se revelarem dualísticas e dicotômicas, traçando fronteiras de dentro e fora, de materno e estrangeiro, de igual e diferente, de familiar e estranho. No imaginário desse aluno-professor, portanto, a língua que o deslumbra mantémse intocada, o que a coloca em certa relação com o real e com o objeto a (resíduo não-simbolizável) da psicanálise. Percebe-se, portanto, que não há, efetivamente, a experiência de entrega do sujeito à(s) língua(s) marcada(s) como estrangeira(s) - no caso, a inglesa -, já que o sujeito parece não querer perder os traços de identidade que o constituem primeiramente (provavelmente, $o$ que ocorreu na língua dita materna). Há, de certa forma, uma negação em aceitá-la(s) como parte de si e, portanto, não há a produção de um signo (significante) que a remeta ao simbólico. Assim, o que parecia remeter ao desejo do sujeito, no primeiro recorte (no deslumbramento em relação à língua inglesa), não se sustenta em seu dizer, já que A1 não se responsabiliza por aquilo (a língua inglesa) que diz deslumbrá-lo e não assume os riscos (a incerteza) dessa escolha.

Trazemos, a seguir, para a discussão, outros recortes pertencentes ao dizer de outro entrevistado. A3 retoma o imaginário de língua estrangeira associado ao discurso amoroso, projetando, nesse caso, como objeto de amor, a língua japonesa:

RD4: No meu caso/ como eu sou criada no interior/ eu num tive contato com a língua inglesa/ eu tive contato com a língua japonesa/ porque eu fui criada no meio dos japoneses// Eu sou de Assaí/ e lá era uma cidade tipicamente de japoneses/ E eu estudava junto com os

${ }^{6} \mathrm{O}$ grande outro (Outro), conceito proposto pela psicanálise, não se refere, diretamente, a um outro indivíduo, mas ao papel da linguagem, da lei, da cultura, ou seja, do simbólico, na constituição do sujeito. Pode referir-se, também, de modo geral, ao inconsciente e suas formaçóes. 
japoneses/ e eles tinham a escola brasileira e a escola japonesa/ E minha maior vontade seria aprender o japonês/ só que havia uma separação das duas raças ali/ entendeu?/ Mas eu acho que o meu interesse por outra língua partiu disso aí/ que eu tinha assim paixão/ até os pequeninhos tentavam ensinar pra gente a língua japonesa/ e o inglês mesmo tava completamente fora

Podemos associar o “interesse” por língua estrangeira de A3 a um possível "desejo" pela língua japonesa, já que há uma falta, uma impossibilidade, que circunda o dizer do sujeito, impedindo a realização desse desejo: minha maior vontade seria aprender o japonês/ só que havia uma separação das duas raças ali. Essa língua não parece associada à noção de um "código" de comunicação, mas representando uma cultura e uma identidade desejada pelo sujeito (o que vai ser narrado pelo enunciador em outros trechos de seu dizer).

O sujeito tenta justificar, racionalizar, seu interesse pelas outras línguas a partir dessa experiência "frustrada", que impulsiona seu desejo: a língua imaginada que deseja só existiria como objeto alucinado. Na objetificação dessa paixão, a língua japonesa se coloca, fantasisticamente, como suporte para a demanda (de amor) do sujeito. No entanto, esse objeto jamais poderá suprir a falta inerente ao sujeito que fala. Apenas vem tamponar parcialmente a demanda de satisfação do sujeito ou, como acontece com A1, o sujeito volta-se para outro objeto - outra língua (RD2) -, já que não é capaz de elaborar uma relação de transformação subjetiva com a língua inglesa, transferindo sua demanda de amor para outro objeto amável e, talvez, mais acessível (a língua espanhola).

Se, por um lado, A3 manifesta discursivamente identificações com o idioma japonês, o qual parece estar associado à causa do desejo, por outro, o inglês é citado duas vezes como uma língua com a qual o eu não compartilha "familiaridade" (não tinha contato; estava completamente fora). Este "estar fora" remete novamente à constituição de um fora/dentro imaginário, que é criado a partir de uma injunção histórica, das relações de poder que se estabelecem socialmente e que remetem um dos lados para o "dentro", tornando-o, assim, hegemônico no corpo social. Aquilo que é expulso remete-se a um "fora", que pode ser identificado com o estrangeiro, com o diferente, como já apontamos no discurso de A1.

No entanto, essas relações dicotômicas (como as de dentro e fora, por exemplo) confundem-se na constituição subjetiva dos indivíduos, cujo inconsciente cria e desloca tais posiçôes. Ora, em seu dizer, A3 identifica-se, 
imaginariamente, com a língua japonesa, com seu povo (eu fui criada no meio dos japoneses; eu estudava junto com os japoneses; os pequeninhos tentavam ensinar pra gente a lingua japonesa) e sua cultura, tornando-a um "dentro" para o sujeito. Ora, esta língua, entretanto, remete também a um fora, no qual o sujeito não se insere ou não consegue se inserir (só que havia uma separação das duas raças ali). Esse movimento dual aponta para a cisão do sujeito e para sua constituição heterogênea. $\mathrm{O}$ idioma japonês como o Outro, inconsciente, assume diferentes posições na constituição subjetiva de A3, da qual temos pequenos indícios em suas formulaçóes.

Se, no recorte discursivo 4, o enunciador narra sua paixão pela língua japonesa, a qual associamos à falta constitutiva do sujeito, no recorte a seguir (RD5), o sujeito, constituído pelo mundo social, pela voz de muitos outros, pelos vários discursos que o cercam, pela economia globalizada, ou seja, pelo Outro, recomenda a seus alunos que estudem inglês por necessidade. Ou seja, nesse momento, aquele "exterior radical" assume a forma de uma tecnologia de si, estabelecendo uma forma de agenciamento para a conduta dela, professora, e dos alunos, impondo-lhes, da sua posição de poder, a necessidade de estudar o inglês:

RD5: se eles não gostam do inglês/ eles aprendam por necessidade/ porque qualquer lugar que eles forem.../ é uma língua que você.../ se ele for no Japão/ ele vai encontrar alguém que fale inglês, né?/ Então eles precisam aprender por necessidade// Eu tenho uma filha que diz que vai pros Estados Unidos/ e eu falo.../ e ela não gosta de inglês/ Então/ o primeiro passo é que nós vamos ter que colocar você no inglês/ como é que chega num país sem saber falar nada... de inglês?!

Nesse recorte, pela análise da materialidade lingüística, temos um outro exemplo da heterogeneidade constitutiva do sujeito. Notamos que, por um lado, o dizer do enunciador, em sua posição de professor, parece aqui "dominado" pela imposição social (a exigência social de aprender o inglês), o que deixa marcas na materialidade lingüística (precisam aprender por necessidade). Esse discurso do "exterior" é assumido pelo sujeito como seu, referindo-se a uma demanda social de consumo, da qual o sujeito se apropria como se fosse sua e que é tratada por ele como uma "necessidade". Por outro lado, a materialidade lingüística deixa entrever o conflito que o constitui subjetivamente e que marca um lugar de falta (de desejo), projetado nesse dizer. Ao exemplificar um lugar em que o inglês também seria falado, o eu enuncia, como exemplo, o Japão, aquele "lugar" imaginário onde as pessoas falam a 
(sua) língua desejada, o japonês (se ele for no Japão). É numa pequena "brecha" do discurso como esta que podemos vislumbrar indícios da constituição subjetiva dos alunos-professores em que coabitam as injunções sociais e o desejo, o qual assume formas plurais na tentativa de simbolização.

Ainda em RD5, quando fala da filha, o enunciador, assumindo, então, a posição de mãe, parece conferir à língua inglesa o papel de uma mera "ferramenta" de comunicação (portanto, um "externo" ao sujeito) necessária para quem quer ir para os Estados Unidos, ainda que não pareça haver identificação com aquela língua (e ela não gosta de inglês). Assim, há uma visão utilitarista de língua que subjaz ao dizer de A3, já que o inglês seria apenas um instrumento de acesso a algo do outro que parece invejado pelo sujeito.

Parece pertinente afirmar, então, que as tecnologias de si que organizam os agenciamentos do sujeito também o constituem inconscientemente, o que sugere, mais uma vez, a divisão e a heterogeneidade constitutiva do sujeito. No caso de A3, o sujeito assume diversas formaçóes discursivas que o constituem e que são por ele reproduzidas em seu dizer, revelando, nesse caso, o conflito que existe no sujeito em relação à visão de língua estrangeira como necessidade e como lugar em que o desejo, ainda que na precária relação com o simbólico, também se coloca em jogo.

\section{Algumas considerações finais}

Podemos concluir, ainda que provisoriamente, que o discurso da língua estrangeira como necessidade e demanda social e o discurso do "desejo" das línguas, já interpretado pelo viés de uma sociedade de consumo, tocam-se, imbricam-se e colocam em questão o aprender línguas como uma possibilidade de gozar na língua do outro, pois o sujeito invejaria esse lugar privilegiado, completamente ilusório, que o outro ocupa em seu imaginário (PRASSE, 1997). No entanto, ao tomar a língua como um instrumento de poder, de obtenção de gozo, ainda que parcial, já que se remete a uma busca incessante pelo (impossível) preenchimento da sua falta constitutiva, o sujeito anula a possibilidade de "entrar" nessa língua, de compor relações com ela que se dariam não só na ordem do imaginário, mas também no campo do simbólico, criando novos significantes, num processo metafórico em que diferentes relaçôes de sentido seriam construídas e poderiam fazer signo no sujeito.

Parece-nos, portanto, que o ensino-aprendizagem de línguas, voltado somente para a obtenção de habilidades e que postula a elas um lugar de mero instrumento de comunicação, atribui às línguas ditas estrangeiras uma posição 
de exterior em relação à subjetividade, o que justificaria, portanto, a sua nomeação como "língua estrangeira". Além disso, tal visão é reducionista, pois apela para o discurso da língua apenas como necessidade, deixando de lado seu potencial de construção da identidade. Com isso, atribui ao professor de línguas o papel de mero "reprodutor" desse discurso da "demanda social".

Retomando a visão de língua como lugar de falta, é possível elaborar, com os professores e alunos, novas relações, em torno da língua que aprendem e com o próprio processo de aprendizagem, levando em conta sentimentos que circundam o "desejo" de qualquer sujeito: o risco, a surpresa, o medo e também a falibilidade, pois só se faz sujeito em outra língua e nela se constrói um saber, quando se parte do pressuposto que aquela não é uma propriedade, mas apenas, em nós, um "lugar" provisório (inconsciente) em que persiste uma falta e que "vive" sedento por criar novos significantes, a fim de poder lidar com a estrangeiridade que habita qualquer língua e sujeito.

\section{Referências}

BARTHES, R. (1977). Fragmentos de um discurso amoroso. Rio de Janeiro: Livraria Francisco Alves, 1990.

CASTORIADIS, C. (1975). A instituição imaginária da sociedade. São Paulo: Paz e Terra, 1986.

CELADA, M. T. O espanhol para o brasileiro: uma língua singularmente estrangeira. 2002. Tese (Doutorado) - IEL/UNICAMP , Campinas, 2002.

FINK, B. (1995). O sujeito lacaniano: entre a linguagem e o gozo. Rio de Janeiro: Jorge Zahar Editor, 1998.

FORBES, J. (2003). Você quer o que deseja? Rio de Janeiro: Editora Best Seller, 2005.

FOUCAULT, M. Ditos e Escritos $V$. Rio de Janeiro: Editora Forense Universitária, 2004a.

. Microfísica do poder. São Paulo: Graal, 2004b.

FREUD, S. (1919). O estranho. Ed. Standard Bras., v. XVII. Rio de Janeiro: Imago, 1996.

. (1920). Além do princípio do prazer. Ed. standard bras., v. XVIII. Rio de Janeiro: Imago, 1996.

NASIO, J.-D. (1992). 5 liçôes sobre a teoria de Jacques Lacan. Rio de Janeiro: Jorge Zahar, 1993. 
PRASSE, J. O desejo das línguas estrangeiras. Revista internacional: A clínica lacaniana, Rio de Janeiro: Companhia de Freud, ano 1, n.1, p.63-73, jun. 1997.

ROSE, N. Como se deve fazer a história do eu? Educação \& Realidade, Porto Alegre, UFRGS, jan./jul. 2001a.

(1996). Inventando nossos eus. In: SILVA, T. T. da. Nunca fomos humanos. Belo Horizonte: Autêntica, 2001 b.

Recebido em março de 2008. Aprovado em junho de 2008. 